\title{
The $\mathrm{Au}_{10}{ }^{+}$Cluster is a Strong, Broadband Mid
}

\section{Infrared Chromophore}

Alice E. Green, ${ }^{1}$ Alexander S. Gentleman, ${ }^{1}$ Wieland Schöllkopf, ${ }^{2}$ André Fielicke, ${ }^{2,3^{*}}$ and Stuart R. Mackenzie ${ }^{1 *}$

1 Department of Chemistry, University of Oxford, Physical and Theoretical Chemistry Laboratory, South Parks Road, Oxford, United Kingdom, OX1 3QZ

2 Fritz-Haber-Institut der Max-Planck-Gesellschaft, Faradayweg 4-6, 14195 Berlin, Germany

3 Institut für Optik und Atomare Physik, Technische Universität Berlin, Hardenbergstraße 36, 10623 Berlin

\section{Corresponding Author}

*stuart.mackenzie@chem.ox.ac.uk

*fielicke@fhi-berlin.mpg.de

ORCID: AEG: 0000-0002-6897-1247

ASG: $0000-0003-3820-2488$

WS: $\quad 0000-0003-0564-203 \mathrm{X}$

AF: $\quad 0000-0003-0400-0932$

SRM: 0000-0002-3166-8631 


\section{ABSTRACT}

We report an intense broadband mid infrared absorption band in the $\mathrm{Au}_{10}{ }^{+}$cluster in a region in which only molecular vibrations would normally be expected. Observed in the infrared multiple photon dissociation spectra of $\mathrm{Au}_{10} \mathrm{Ar}^{+}, \mathrm{Au}_{10}\left(\mathrm{~N}_{2} \mathrm{O}\right)^{+}$and $\mathrm{Au}_{10}(\mathrm{OCS})^{+}$, the smooth feature stretches $700-3400 \mathrm{~cm}^{-1}(\lambda=14-2.9 \mu \mathrm{m})$. Calculations confirm unusually low-energy allowed electronic excitations consistent with the observed spectra. In $\mathrm{Au}_{10}(\mathrm{OCS})^{+}$, IR absorption throughout the band drives OCS decomposition resulting in CO loss, providing an alternative method of bond activation/breaking.

\section{TOC GRAPHICS}

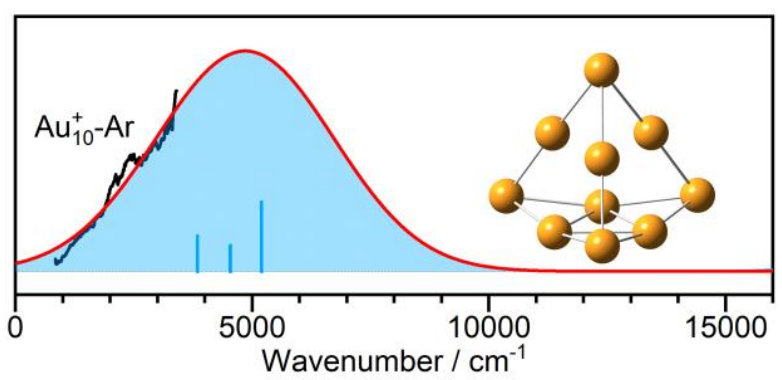

$\mathrm{Au}_{10}{ }^{+}$exhibits a remarkable, broad absorption feature in the mid infrared where only molecular vibrational bands would normally be expected. 
The optical properties of atomically precise metal clusters and nanoparticles continue to attract interest due to their potential in sensing [1], labelling [2], imaging [3], biological [4], and medical applications $[5,6]$. Gold plays a central role in this activity: the localised surface plasmon resonance in small gold nanoparticles has been well characterised and finds many practical applications [7]. For small gold clusters, a detailed understanding of the electronic and geometric structure offers the prospect of tuning cluster properties, including reactivity.

Here, we report a strong, broad absorption band in the $\mathrm{Au}_{10}{ }^{+}$cluster which extends throughout the mid infrared region where only molecular vibrational bands would normally be expected. In the cluster size range studied $\left(\mathrm{Au}_{n}{ }^{+}, 3 \leq n \leq 12\right)$, this absorption band is unique to $n=10$ and, remarkably, is preserved when $\mathrm{Ar}, \mathrm{N}_{2} \mathrm{O}$ or OCS are adsorbed.

The structures of small charged gas-phase gold clusters have been studied using a wide variety of spectroscopic techniques [8-10]. Using ion mobility mass spectrometry Kappes and coworkers revealed remarkable planar ground state structures for $n \leq 7\left(\mathrm{Au}_{n}{ }^{+}\right)$and $n \leq 11$ for $\mathrm{Au}_{n}{ }^{-}$ clusters [11-13]. Far infrared action spectroscopy of $\mathrm{Au}_{n}{ }^{+}(n \leq 9)$ recently confirmed these structures [14-16] and visible photodissociation spectroscopy has been used to probe structure around the 2D to 3D transition [17] and other sizes [18-29]. Various studies of ligated clusters also show evidence of this large geometrical change [30-32].

Larger gold clusters exhibit a range of geometrical structures $[33,34]$ from the open $\mathrm{Au}_{11}{ }^{+}$ structure to close-packed structures, including quasi-tetrahedral $\mathrm{Au}_{10}{ }^{+}[11]$ and perfectly tetrahedral $\mathrm{Au}_{20}$ [35]. Interestingly, the latter has an anomalously large HOMO-LUMO gap $(1.8 \mathrm{eV})[36,37]$ which, along with the cluster structure, survives cluster deposition onto an ultrathin sodium chloride surface [38]. Petrar et al. also predict a large HOMO-LUMO gap $(3.88 \mathrm{eV})$ for $\mathrm{Au}_{10}{ }^{2+}$ [39]. The SOMO-LUMO transition in $\mathrm{Au}_{10}{ }^{+}$, as a potential carrier for the spectrally broad absorption feature observed, is a key focus of this paper. 
Many structural aspects of gold clusters are explained by electronic shell structures [40,41]. The unpaired $6 s$ electron in the gold atom $\left([\mathrm{Xe}] 4 f^{14} 5 d^{10} 6 s^{1}\right)$ often leads to it behaving like an alkali metal [42] with delocalisation of the valence electrons in clusters leading to magic numbers corresponding to electron (sub-)shell closures at $2(1 S), 8(1 P), 18(1 D), 20(2 S), \ldots$ within spherical jellium systems [43-46]. Similar shells persist in alternative symmetries $[47,48]$. In tetrahedral structures, magic numbers arise for $2,8,10,16,20, \ldots$ electrons with the largest steps in stability at 2,8 and 20. With 20 valence electrons, $\mathrm{Au}_{20}$ comprises a fully stabilised shell favouring a tetrahedral symmetry [35-37,47]. Despite their stability, $\mathrm{Au}_{20}$, and other magic number clusters, can be highly reactive with charge transfer from a support $[49,50]$.

Other gold cluster properties, e.g., the stability of $\mathrm{Au}_{7}^{+}$and $\mathrm{Au}_{9}{ }^{+}$in fragmentation experiments, can also be explained by shell structures [48,51-53]. These properties can be used to tune cluster chemistry. For example, replacing core ligands in a $\mathrm{Au}_{11}\left(\mathrm{PH}_{3}\right)_{7} \mathrm{Cl}_{3}$ cluster with $\mathrm{O}_{2}$ leads to partial electron donation from the 9 valence electron cluster, facilitating $\mathrm{CO}$ oxidation [54]. Similar donation explains the fact that only $\mathrm{Au}_{10}{ }^{+}$and $\mathrm{Au}_{22}{ }^{+}$clusters bind $\mathrm{O}_{2}$ with a superoxo motif thereby achieving stable 8- and 20-electron structures, respectively [55]. All even $n \mathrm{Au}_{n}{ }^{+}$clusters have unpaired electrons and the literature is rich with odd-even oscillations in physical and chemical properties [34,56-62]. The subject of this study, $\mathrm{Au}_{10}{ }^{+}$, with its 9 valence electrons, is shown to exhibit a very small $(\sim 0.5 \mathrm{eV})$ SOMO-LUMO gap with several low-lying optically accessible excited electronic states.

Here, we report a common intense, broad absorption feature in the infrared multiple-photon dissociation (IRMPD) spectra of three isolated $\mathrm{Au}_{10} \mathrm{X}^{+}$systems: $\left[\mathrm{Au}_{10} \mathrm{Ar}\right]^{+},\left[\mathrm{Au}_{10} \mathrm{OCS}\right]^{+}$, and $\left[\mathrm{Au}_{10} \mathrm{~N}_{2} \mathrm{O}\right]^{+}$. These show all the characteristics of a low energy electronic band and timedependent density functional theory (TDDFT) simulations confirm an anomalously low SOMO-LUMO gap in $\mathrm{Au}_{10}{ }^{+}$with allowed $1^{\text {st }}$ vertical excitation consistent with the observed 
band. Full experimental and computational details are given in the Supporting Information, which includes refs [63-66] and [67-86], respectively. Briefly, clusters are generated by laser ablation of a gold target and cooled by collision in a clustering channel maintained at 105-300 K. Adsorbates are introduced either via a late mixing valve (OCS, $\mathrm{N}_{2} \mathrm{O}$ ) $[62,87]$ or seeded in the helium carrier gas (Ar). Previous experiments have shown that clusters thermalise effectively to the temperature of such sources [88].

Figure 1(a) shows the IRMPD spectra in the mid IR region accessible with the Fritz Haber Institute free electron laser [63]. The spectra are recorded by loss of the adsorbate and there is no evidence of fragmentation of the metal cluster itself (see Figure S3). In each system, the spectrum comprises a smooth continuous absorption from $700 \mathrm{~cm}^{-1}$ upwards and has not reached its peak by $3400 \mathrm{~cm}^{-1}$, the upper limit of our measurements. In $\left[\mathrm{Au}_{10} \mathrm{OCS}\right]^{+}$and $\left[\mathrm{Au}_{10} \mathrm{~N}_{2} \mathrm{O}\right]^{+}$, the narrow OCS and $\mathrm{N}_{2} \mathrm{O}$ molecular vibrational absorption features are clearly visible on top of this broad background and have been discussed elsewhere $[62,87]$.

Figures 1(b)-(d) show that this intense, broad absorption band is unique to the $n=10$ cluster in the $n=3-12$ range studied here (see also Figure S3). For all other cluster sizes, only the vibrational bands of the molecularly-adsorbed $\mathrm{N}_{2} \mathrm{O}$ or OCS are observed in this range.

The observation of this broad absorption band in the Ar-tagged $\mathrm{Au}_{10}{ }^{+}$cluster is revealing. In the absence of molecular chromophores, no vibrational transitions are expected at wavenumbers $>250 \mathrm{~cm}^{-1}$ (see ref [14] and Supporting Information) suggesting this is a lowenergy, $\mathrm{Au}_{10}{ }^{+}$-centred, electronic absorption. This interpretation is consistent with the same smooth featureless appearance with all three adsorbates. Common in larger clusters and nanoparticles with their higher density of states and band-like structures, low energy HOMOLUMO transitions are unusual in small clusters where shell structures typically lead to larger state separations. Furthermore, these transitions are often either within the same shell or 
between shells with angular momentum quantum numbers differing by 2 , and are thus dipole forbidden.

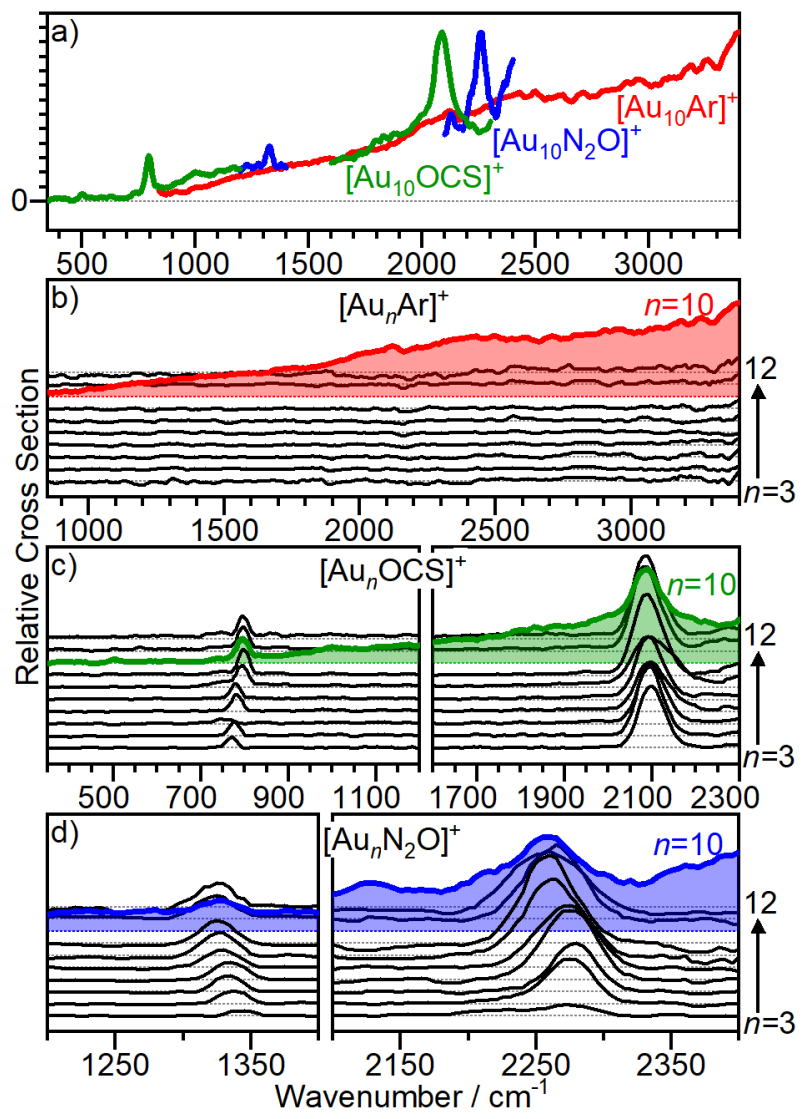

Figure 1. a) IRMPD spectra of $\left[\mathrm{Au}_{10} \mathrm{Ar}\right]^{+},\left[\mathrm{Au}_{10} \mathrm{OCS}\right]^{+}$and $\left[\mathrm{Au}_{10} \mathrm{~N}_{2} \mathrm{O}\right]^{+}$across the mid infrared showing persistent background depletion. b), c), d) IRMPD spectra of $\left[\mathrm{Au}_{n}(\mathrm{Ar})\right]^{+}$, $\left[\mathrm{Au}_{n}(\mathrm{OCS})\right]^{+}$and $\left[\mathrm{Au}_{n}\left(\mathrm{~N}_{2} \mathrm{O}\right)\right]^{+}(n=3-12)$, respectively illustrating the unique nature of the $n=10$ cluster in each case. Intensity is plotted as a relative cross section, corrected for laser power.

Low-lying excited electronic states have, however, recently been proposed by Hansen et al. [60] to account for short radiative lifetimes of some small $\mathrm{Au}_{n}{ }^{+}(n<20)$ clusters, though not particularly $n=10$. Our IRMPD technique is complementary to this method but sensitive to lower oscillator strengths - the $\mathrm{C}=\mathrm{O}$ and $\mathrm{C}=\mathrm{S}$ stretches in $\left[\mathrm{Au}_{10} \mathrm{OCS}\right]^{+}$, clearly observed in Figure 1(c) (and ref [62]) have oscillator strengths, $f=2 \times 10^{-4}$ and $7 \times 10^{-6}$, respectively [89]. This is not the first time that electronic states have been observed by IRMPD - Bakker and coworkers having reported low energy electronic bands in $\mathrm{Ta}_{5} \mathrm{C}_{3}[90]$. 
It is notable that the systems in which we observe this broad absorption all involve closedshell adsorbates (Ar, OCS, $\mathrm{N}_{2} \mathrm{O}$ ). These present minimal perturbation to the electronic structure of the $\mathrm{Au}_{10}{ }^{+}$. No such feature was observed in the spectra of $\left[\mathrm{Au}_{10} \mathrm{O}_{2}\right]^{+}$or $\left[\mathrm{Au}_{10} \mathrm{NO}\right]^{+}$with their open-shell adsorbates $[55,91]$. With 9 valence electrons, $\mathrm{Au}_{10}{ }^{+}$has one more than a stable 8electron sub-shell [40]. This outer electron is delocalised around the quasi-tetrahedral structure [11] and readily donates into the $\pi^{*}$ orbital of $\mathrm{O}_{2}$ generating superoxo-species [55]. All even $n \mathrm{Au}_{n}{ }^{+}$clusters activate nitric oxide molecules by electron donation into the NO anti-bonding $\pi^{*}$ orbital [91]. Figures S13-S16 show simulated vibrational and electronic spectra of $\mathrm{Au}_{10}{ }^{+}-$ $\mathrm{L}\left(\mathrm{L}=\mathrm{Ar}, \mathrm{OCS}, \mathrm{N}_{2} \mathrm{O}, \mathrm{NO}\right.$ and $\left.\mathrm{O}_{2}\right)$.

The structures of gold clusters clearly reflect a complex balance of factors including electronic shell structure, $s-d$ hybridization, relativistic effects and pseudo Jahn-Teller distortion. We have investigated low energy electronic excitations in low-lying isomers of the clusters studied here by using TDDFT to calculate the first vertical excitation energies. Many clusters in this range exhibit energetically low-lying isomers $[11,12,30]$ and a detailed search was completed for $\mathrm{Au}_{n}{ }^{+} n=2-10$ (see Supporting Information for structures and vertical excitations of all low-lying isomers found). Figure 2 shows the calculated vertical excitation energies for cluster structures identified by Kappes and coworkers in their ion mobility studies [11], and confirmed in recent far infrared spectroscopic studies $(n \leq 9)$ [14]. A pronounced alternation is observed with transitions consistently higher for the (closed-shell) odd $n$ clusters than for adjacent even $n$ clusters.

For $\mathrm{Au}_{10}{ }^{+}$, density functional theory (DFT) predicts at least five isomers within $0.2 \mathrm{eV}$ of the putative global minimum structure (Figure S5). Kappes and coworkers assigned $\mathrm{Au}_{10}{ }^{+}$ definitively to a distorted tetrahedral isomer whose calculated cross section $\left(77.4 \AA^{2}\right)$ matches the ion mobility data $\left(77.8 \pm 2 \AA^{2}\right)$ better than that of the lowest energy structure $\left(81.8 \AA^{2}\right)[11]$. 
This quasi-tetrahedral $\mathrm{Au}_{10}{ }^{+}$isomer (which lies $0.05 \mathrm{eV}$ above the putative global minimum) has a particularly low calculated first vertical excitation energy (see Figure 2) consistent with the spectrum observed here. This is a direct, dipole-allowed SOMO-LUMO transition for which the calculated oscillator strength is high $(f=0.0019)$.

$\mathrm{Au}_{12}{ }^{+}$also has a low energy calculated transition but we see no evidence in our spectra for an equivalent infrared feature. For some cluster isomers (e.g., $n=2,6,8)$ the HOMO- $\rightarrow$ SOMO excitations are lower in energy than the $\mathrm{SOMO} \rightarrow$ LUMO transition, but the oscillator strengths for such transitions are typically markedly lower (see Figures S8, S12).

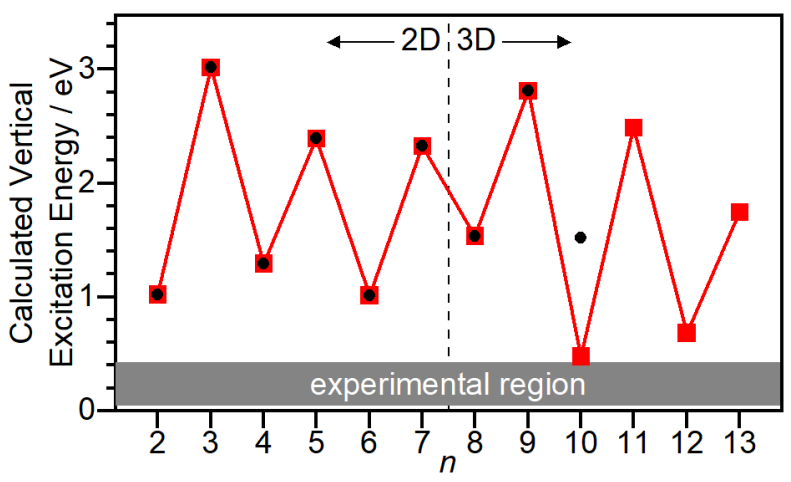

Figure 2. First vertical excitation energies for $\mathrm{Au}_{n}{ }^{+}(n=2-13)$ calculated using TDDFT using the UB3P86-SDD [67-70] functional-basis set combination (including $\mathrm{HOMO} \rightarrow$ LUMO and HOMO- $\rightarrow$ SOMO transitions). Solid black circles indicate excitations from the lowest energy structures, whereas the red squares (and line) are from structures assigned in previous experiments [11,14]. For $n=2-9$, these are the same structures. For $\mathrm{Au}_{10}{ }^{+}$, the structure assigned by ion mobility [11] lies $0.05 \mathrm{eV}$ higher than the global minimum (see text and Figure S5 for details). The grey shaded area illustrates the spectral region investigated (Figure 1).

The presence of allowed low-lying electronic transitions in 9 valence electron $\mathrm{Au}_{10}{ }^{+}$can be better understood in terms of a combination of electronic and geometrical structure as illustrated in Figure 3, which shows the calculated low-lying states involved, arising primarily from the ten $\mathrm{Au} 6 s$ orbitals. The experimentally-determined structure is a pseudo Jahn-Teller distorted tetrahedron [11]. The SOMO orbital in $\mathrm{Au}_{10}{ }^{+}$is highly diffuse and the HOMO- 
$1 \rightarrow$ SOMO gap large ( $>3 \mathrm{eV}$ from ground state orbital energies) reflecting the stability of the 8-electron system. In $T_{d}$, unlike in spherical symmetry, the $2 \mathrm{~S}$ symmetry adapted orbital lies just below 1D, which is split into $\mathrm{E} \oplus \mathrm{T}_{2}$ components [47] (and then further to $\mathrm{A}_{1} \oplus \mathrm{E} \oplus \mathrm{E}$ in distortion to $C_{3 v}$ ), leading to the anomalously low SOMO-LUMO gap for such a small cluster. The strong state mixing driven by the distortion, coupled with the lack of inversion symmetry, provides the oscillator strength to a transition which, in spherical symmetry, would be dipole forbidden. Tables S3 and S4 give calculated oscillator strengths for the lowest energy $(<0.7$ $\mathrm{eV}$ ) transitions involved which increase by a factor 3.7 upon $T_{d} \rightarrow C_{3 v}$ distortion as all transitions $\mathrm{A}_{1} \rightarrow \mathrm{A}_{1}, \mathrm{E}, \mathrm{E}$ become allowed.

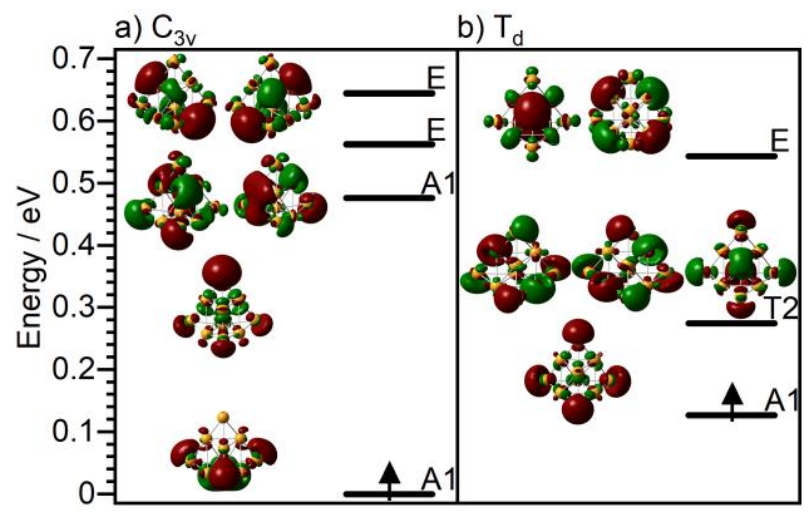

Figure 3. Orbital visualisation of states involved in the lowest vertical transitions from the TDDFT calculations for: a) the $\mathrm{Au}_{10}{ }^{+}$structure assigned by ion mobility [11], and b) a tetrahedrally-constrained structure. All are single transitions from the unpaired alpha electron in the SOMO to 5 low-lying states, with degenerate levels indicated. Energies are relative to the ground state of the $C_{3 v}$ isomer and the next vertical excitations lie at 2.63 and $2.74 \mathrm{eV}$ for $T_{d}$ and $C_{3 v}$, respectively.

Figure 4(a) shows a summary of the calculated lowest energy electronic transitions of $\mathrm{Au}_{n}{ }^{+}$ ( $n=2-13)$ and their corresponding oscillator strengths, including the predicted low energy transitions of $\mathrm{Au}_{10}{ }^{+}$shown in Figure 3. Figures 4(b) and 4(c) represent an attempt to: i) fit the full spectrum of the electronic band, and ii) use it to compare the calculated oscillator strengths for the electronic and vibrational bands in $\mathrm{Au}_{10}(\mathrm{OCS})^{+}$with those observed experimentally. 
Clearly, we have not recorded the entire $\mathrm{Au}_{10}{ }^{+}$absorption band here. Nevertheless, following Gloess et al. [17] and Shayeghi et al. [92], Figures 4(b) and 4(c) show that Gaussian profiles centred on the calculated vertical excitation energies of $\mathrm{Au}_{10}{ }^{+}$account well for the spectrum observed and permit an estimate of the width of the spectral band of $4410 \mathrm{~cm}^{-1}(\mathrm{ca} .0 .55 \mathrm{eV})$. Several factors likely contribute to this spectral width. The state mixing arising from the pseudo Jahn Teller deformation leads to avoided crossings between the states involved. In addition to providing a strong transition strength dependence on this deformation coordinate, this provides a mechanism for rapid, diabatic crossing back to the ground state leading to lifetime broadening.

The relative intensities of the simulated vibrational and electronic components of the spectra are compared in Figure 4(c). By way of example, we have used the $\mathrm{Au}_{10} \mathrm{Ar}^{+}$fit for the electronic band to extract linewidths of 71,24 , and $20 \mathrm{~cm}^{-1}$ for the OCS fundamental modes in $\left[\mathrm{Au}_{10} \mathrm{OCS}\right]^{+}$at $c a .500,795$ and $2084 \mathrm{~cm}^{-1}$, respectively. Using these linewidths, the calculated relative oscillator strengths of the electronic $\left(\mathrm{Au}_{10}{ }^{+}\right.$-centred) and vibrational $\left(\left[\mathrm{Au}_{10} \mathrm{OCS}\right]^{+}\right)$ contributions show excellent agreement with the experimental spectrum (see Figure 4(c) inset) providing some confidence in the simulations.

In addition to capturing the observed $\mathrm{Au}_{10}{ }^{+}$band, our TDDFT simulations predict a similar set of low-lying electronically excited states for $\mathrm{Au}_{12}{ }^{+}$(see Figure 4a). In this case an allowed SOMO-LUMO band is predicted ca. $0.2 \mathrm{eV}$ higher than that in $\mathrm{Au}_{10}{ }^{+}$. We find no evidence in our spectra for such a band but this may simply indicate a narrower spectral linewidth which is likely to be different for each cluster size and/or transition. It would be interesting to search further to the blue for such a band. For comparison, electronic bands in the visible $(2-3 \mathrm{eV})$ region for $\mathrm{Au}_{7}^{+}, \mathrm{Au}_{8}{ }^{+}$and $\mathrm{Au}_{9}{ }^{+}$have typical spectral widths of $0.11-0.16 \mathrm{eV}$ [17]. 


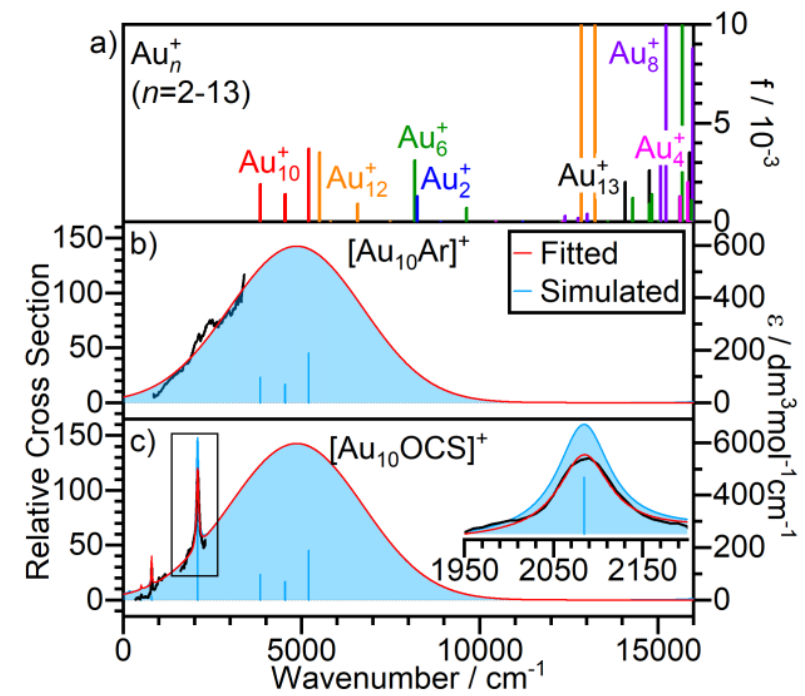

Figure 4. a) Calculated low energy vertical excitations of $\mathrm{Au}_{n}{ }^{+}(n=2-13)$ assuming structures assigned in previous experiments $[11,14] . \mathrm{b})$ and c) IRMPD spectra of $\left[\mathrm{Au}_{10} \mathrm{Ar}\right]^{+}$ and $\left[\mathrm{Au}_{10} \mathrm{OCS}\right]^{+}$, respectively (black lines), and corresponding fits in red. Calculated bands are reported as $\varepsilon$, the molar absorption coefficient and blue shaded areas give the overall simulated spectra with individual peak centres marked. (inset) Relative intensity of the OCS vibrational band at $2084 \mathrm{~cm}^{-1}(\mathrm{C}=\mathrm{O}$ stretch) assuming fitting of the electronic band. Further fitting details are given in the Supporting Information.

We have previously reported infrared-induced bond breaking in $\left[\mathrm{Au}_{n} \mathrm{OCS}\right]^{+}$(even $n$ ) entrance channel complexes following pumping of the OCS vibrational modes [62]. In $\mathrm{Au}_{10}(\mathrm{OCS})^{+}$, both simple OCS loss and CO loss (reflecting OCS decomposition) are observed throughout the broad absorption band reported here. Figure 5 shows the branching ratio for the CO-loss (i.e., reactive channel) as the absolute enhancement in the $\mathrm{Au}_{10} \mathrm{~S}^{+}$signal as a fraction of $\mathrm{Au}_{10}(\mathrm{OCS})^{+}$depletion. Clearly, electronic excitation (e.g., in the region 900-1900 $\mathrm{cm}^{-1}$ ) drives bond-breaking chemistry every bit as efficiently as does direct vibrational pumping (at $795 \pm 20 \mathrm{~cm}^{-1}$ and $\left.2084 \pm 50 \mathrm{~cm}^{-1}\right)$. 


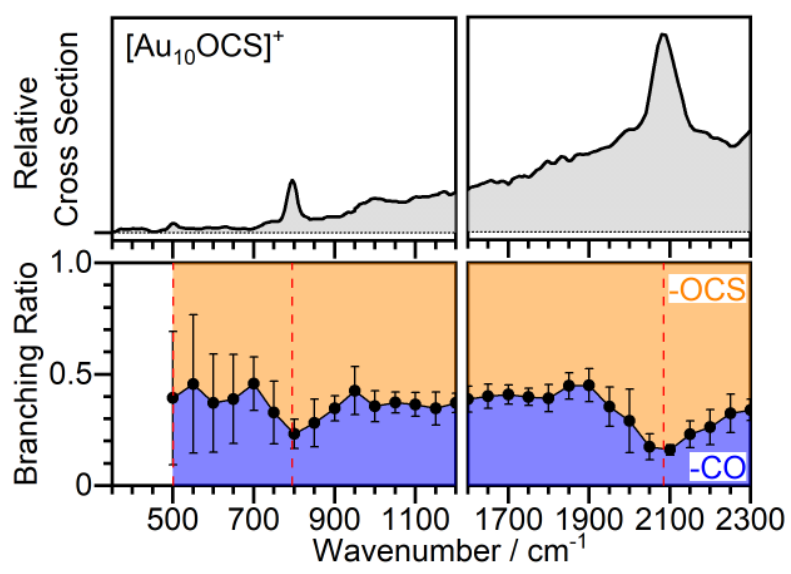

Figure 5. Branching ratio for $\mathrm{CO}$ loss following photodissociation of $\left[\mathrm{Au}_{10} \mathrm{OCS}\right]^{+}$recorded in enhancement of $\left[\mathrm{Au}_{10} \mathrm{~S}\right]^{+}$. Uncertainties reflect the standard deviation of the averaging applied. Dashed lines indicate $\left[\mathrm{Au}_{10} \mathrm{OCS}\right]^{+}$molecular vibrational bands.

It is likely that both vibrational and electronic absorption ultimately result in the simple heating of the parent cluster until either the $\left[\mathrm{Au}_{10--} \mathrm{SCO}\right]^{+}$or $\left[\mathrm{Au}_{n} \mathrm{~S}-\mathrm{CO}\right]^{+}$dissociation limit is reached. For even $n$ clusters, the OCS binding energy $(c a .0 .5 \mathrm{eV})$ is comparable with the highest barrier along the OCS dissociation coordinate [62]. We have not undertaken an intensity-dependence study but, under the conditions employed here, the average cluster has significant internal energy and even one or two photons in this spectral region $(0.1-0.3 \mathrm{eV})$ is likely to be sufficient to drive fragmentation on the $\mu$ s timescale required. It is equally possible, however, that the excited electronic state, although having the same multiplicity as the ground state, could lead to interesting new chemistry. As indicated by the orbital visualisation in Figure 3, the electronic excitation drives charge transfer from gold atoms within the cluster to the apex atoms at which OCS preferentially binds. Certainly, the branching ratio for CO loss is higher (ca. 0.4) in regions of electronic excitation than in spectral regions in which OCS vibrations are excited (around $2084 \mathrm{~cm}^{-1}$ and $795 \mathrm{~cm}^{-1}$ ).

This is the first time we have observed bond-breaking chemistry on the surface of a cluster driven by infrared electronic excitation. Freed from the need to excite discrete vibrational 
quanta, this could lead to interesting cluster surface chemistry such as identification of reactive thresholds and simultaneous excitation of different adsorbates. Unique to $n=10$ in the $\mathrm{Au}_{n}{ }^{+}$size range studied $(n \leq 12)$ this low-lying electronic absorption band makes this an attractive system with which to explore the gas-phase reactivity on different potential energy surfaces.

Any ability to harness these unusual photochemical properties of $\mathrm{Au}_{10}{ }^{+}$for any practical application is, however, likely to depend on the extent to which they survive ligand stabilisation in solution [93,94] or deposition onto a suitable substrate [95]. In this context, by soft-landing clusters in neon matrices, Brune and coworkers have shown that the intense fluorescence of ligand-protected (or protein encapsulated) $\mathrm{Au}_{20}$ clusters is intrinsic to the naked $\mathrm{Au}_{20}$ moiety [96]. Significant recent progress has also been made in our understanding of charge control in model catalytic systems [97-99] and extensive work has characterised the reactivity of sizeselected gold clusters deposited from the gas phase $[49,50,100]$. Notably, Au 8 clusters on $\mathrm{MgO}(001)$ become negatively charged and promote $\mathrm{CO}$ oxidation. $\mathrm{Au}_{8}^{-}$is, of course, isoelectronic with $\mathrm{Au}_{10}{ }^{+}$. In terms of geometrical structure, scanning tunnelling microscopy has shown that the low energy pyramidal form of $\mathrm{Au}_{20}$ survives deposition from the gas phase onto a $\mathrm{NaCl}$ film [38].

It is clear that further experiments remain to fully characterise this unusual spectral feature in $\mathrm{Au}_{10}{ }^{+}$, not least to determine the full spectrum. However, it is hoped that even the observations reported here - in particular the potential for photocatalytic chemistry illustrated in Figure 5 provide sufficient incentive to encourage the surface cluster/nanoparticle community to explore this intriguing system in more detail. 


\section{Supporting Information.}

Further experimental details; additional IRMPD data; comprehensive computational results.

\section{ACKNOWLEDGMENTS}

This work was funded by EPSRC under Programme Grants EP/L005913 and EP/T021675. AEG thanks Magdalen College, Oxford for her Leon and Iris Beghian Scholarship. AF thanks the Deutsche Forschungsgemeinschaft for a Heisenberg grant (FI 893/5). We are grateful to John McGrady and Aras Kartouzian for useful discussions and to the referees whose insightful and constructive comments improved the manuscript. 


\section{REFERENCES}

[1] L. Zhang and E. Wang, Nano Today 9, 132 (2014).

[2] C. A. J. Lin et al., ACS Nano 3, 395 (2009).

[3] H. Liu et al., Adv Mater 31, 1901015 (2019).

[4] S. Choi, R. M. Dickson, and J. Yu, Chem Soc Rev 41, 1867 (2012).

[5] C. Zhou, M. Long, Y. Qin, X. Sun, and J. Zheng, Angew Chem Int Ed 50, 3168 (2011).

[6] J. B. Vines, J. H. Yoon, N. E. Ryu, D. J. Lim, and H. Park, Front Chem 7, 167 (2019).

[7] V. Amendola, R. Pilot, M. Frasconi, O. M. Maragò, and M. A. Iatì, J Phys Condens Matter 29, 203002 (2017).

[8] M. P. Johansson, A. Lechtken, D. Schooss, M. M. Kappes, and F. Furche, Phys Rev A 77, 053202 (2008).

[9] X. Xing, B. Yoon, U. Landman, and J. H. Parks, Phys Rev B 74, 165423 (2006).

[10] H. Häkkinen, B. Yoon, U. Landman, X. Li, H.-J. Zhai, and L.-S. Wang, J Phys Chem A 107, 6168 (2003).

[11] S. Gilb, P. Weis, F. Furche, R. Ahlrichs, and M. M. Kappes, J Chem Phys 116, 4094 (2002).

[12] P. Weis, T. Bierweiler, E. Vollmer, and M. M. Kappes, J Chem Phys 117, 9293 (2002).

[13] F. Furche, R. Ahlrichs, P. Weis, C. Jacob, S. Gilb, T. Bierweiler, and M. M. Kappes, J Chem Phys 117, 6982 (2002).

[14] P. Ferrari, G. L. Hou, O. V. Lushchikova, F. Calvo, J. M. Bakker, and E. Janssens, Phys Chem Chem Phys 22, 11572 (2020).

[15] A. Shayeghi, R. Schäfer, D. M. Rayner, R. L. Johnston, and A. Fielicke, J Chem Phys 143, 024310 (2015).

[16] A. Shayeghi, R. L. Johnston, D. M. Rayner, R. Schafer, and A. Fielicke, Angew Chem Int Ed 54, 10675 (2015).

[17] A. N. Gloess, H. Schneider, J. M. Weber, and M. M. Kappes, J Chem Phys 128, $114312(2008)$.

[18] M. Förstel, K. M. Pollow, K. Saroukh, E. A. Najib, R. Mitric, and O. Dopfer, Angew Chem Int Ed 59, 21403 (2020).

[19] M. Förstel, B. K. A. Jaeger, W. Schewe, P. H. A. Sporkhorst, and O. Dopfer, Rev Sci Instrum 88, 123110 (2017).

[20] M. Förstel, W. Schewe, and O. Dopfer, Angew Chem Int Ed 58, 3356 (2019).

[21] V. E. Kaydashev, E. Janssens, and P. Lievens, J Chem Phys 142, 034310 (2015).

[22] V. Kaydashev, P. Ferrari, C. Heard, E. Janssens, R. L. Johnston, and P. Lievens, Part Part Syst Charact 33, 364 (2016).

[23] S. M. Lang, P. Claes, N. T. Cuong, M. T. Nguyen, P. Lievens, and E. Janssens, J Chem Phys 135, 224305 (2011).

[24] A. Shayeghi, L. F. Pašteka, D. A. Götz, P. Schwerdtfeger, and R. Schäfer, Phys Chem Chem Phys 20, 9108 (2018).

[25] A. Shayeghi, C. J. Heard, R. L. Johnston, and R. Schäfer, J Chem Phys 140, 054312 (2014).

[26] A. Shayeghi, R. L. Johnston, and R. Schäfer, Phys Chem Chem Phys 15, 19715 (2013).

[27] A. Schweizer, J. M. Weber, S. Gilb, H. Schneider, D. Schooss, and M. M. Kappes, J Chem Phys 119, 3699 (2003).

[28] B. K. A. Jaeger, M. Savoca, O. Dopfer, and N. X. Truong, Int J Mass Spectrom 402, 49 (2016). 
[29] B. A. Collings, K. Athanassenas, D. Lacombe, D. M. Rayner, and P. A. Hackett, J Chem Phys 101, 3506 (1994).

[30] A. Fielicke, G. von Helden, G. Meijer, D. B. Pedersen, B. Simard, and D. M. Rayner, J Am Chem Soc 127, 8416 (2005).

[31] G. Dietrich, S. Krückeberg, K. Lützenkirchen, L. Schweikhard, and C. Walther, J Chem Phys 112, 752 (2000).

[32] K. Sugawara, F. Sobott, and A. B. Vakhtin, J Chem Phys 118, 7808 (2003).

[33] A. P. Woodham and A. Fielicke, in Gold Clusters, Colloids and Nanoparticles I. Structure and Bonding, edited by D. Mingos (Springer, Berlin, Heidelberg, 2013).

[34] H. Häkkinen, Chem Soc Rev 37, 1847 (2008).

[35] P. Gruene, D. M. Rayner, B. Redlich, A. F. G. van der Meer, J. T. Lyon, G. Meijer, and A. Fielicke, Science 321, 674 (2008).

[36] J. Li, X. Li, H. J. Zhai, and L. S. Wang, Science 299, 864 (2003).

[37] J. Wang, G. Wang, and J. Zhao, Chem Phys Lett 380, 716 (2003).

[38] Z. Li et al., Sci Adv 6, eaay4289 (2020).

[39] P. M. Petrar, M. B. Sárosi, and R. B. King, J Phys Chem Lett 3, 3335 (2012).

[40] H. Häkkinen, Adv Phys-X 1, 467 (2016).

[41] M. G. Mayer, Science 145, 999 (1964).

[42] W. D. Knight, K. Clemenger, W. A. de Heer, W. A. Saunders, M. Y. Chou, and M. L. Cohen, Phys Rev Lett 52, 2141 (1984).

[43] M. Koskinen, P. O. Lipas, and M. Manninen, Z Phys D: At, Mol Clusters 35, 285 (1995).

[44] W. Ekardt, Phys Rev B 29, 1558 (1984).

[45] W. A. de Heer, Rev Mod Phys 65, 611 (1993).

[46] D. E. Bergeron, A. W. Castleman, Jr., T. Morisato, and S. N. Khanna, Science 304, 84 (2004).

[47] T. Tsukamoto, N. Haruta, T. Kambe, A. Kuzume, and K. Yamamoto, Nat Commun 10, 3727 (2019).

[48] E. Janssens, H. Tanaka, S. Neukermans, R. E. Silverans, and P. Lievens, New J Phys 5, 46 (2003).

[49] M. Arenz, U. Landman, and U. Heiz, ChemPhysChem 7, 1871 (2006).

[50] B. Yoon, H. Häkkinen, U. Landman, A. S. Wörz, J. M. Antonietti, S. Abbet, K. Judai, and U. Heiz, Science 307, 403 (2005).

[51] N. Veldeman, E. Janssens, K. Hansen, J. De Haeck, R. E. Silverans, and P. Lievens, Faraday Discuss 138, 147 (2008).

[52] P. Ferrari, H. A. Hussein, C. J. Heard, J. Vanbuel, R. L. Johnston, P. Lievens, and E. Janssens, Phys Rev A 97, 052508 (2018).

[53] K. Hansen, A. Herlert, L. Schweikhard, and M. Vogel, Phys Rev A 73, 063202 (2006).

[54] O. Lopez-Acevedo, K. A. Kacprzak, J. Akola, and H. Häkkinen, Nat Chem 2, 329 (2010).

[55] A. P. Woodham and A. Fielicke, Angew Chem Int Ed 53, 6554 (2014).

[56] J. K. Gibson, J Vac Sci Technol A 16, 653 (1998).

[57] A. Herlert, S. Krückeberg, L. Schweikhard, M. Vogel, and C. Walther, J Electron Spectrosc Relat Phenom 106, 179 (2000).

[58] S. Becker et al., Z Phys D: At, Mol Clusters 30, 341 (1994).

[59] I. Katakuse, T. Ichihara, Y. Fujita, T. Matsuo, T. Sakurai, and H. Matsuda, Int J Mass Spectrom Ion Processes 67, 229 (1985).

[60] K. Hansen, P. Ferrari, E. Janssens, and P. Lievens, Phys Rev A 96, 022511 (2017). 
[61] E. M. Fernández, J. M. Soler, I. L. Garzón, and L. C. Balbás, Phys Rev B 70, 165403 (2004).

[62] A. E. Green, S. Schaller, G. Meizyte, B. J. Rhodes, S. P. Kealy, A. S. Gentleman, W. Schöllkopf, A. Fielicke, and S. R. Mackenzie, J Phys Chem A 124, 5389 (2020).

[63] W. Schöllkopf, S. Gewinner, H. Junkes, A. Paarmann, G. von Helden, H. Bluem, and A. M. M. Todd, Proc. SPIE 9512, 95121L (2015).

[64] A. Yanagimachi, K. Koyasu, D. Y. Valdivielso, S. Gewinner, W. Schöllkopf, A. Fielicke, and T. Tsukuda, J Phys Chem C 120, 14209 (2016).

[65] N. X. Truong, M. Haertelt, B. K. A. Jaeger, S. Gewinner, W. Schöllkopf, A. Fielicke, and O. Dopfer, Int J Mass Spectrom 395, 1 (2016).

[66] A. E. Green, J. Justen, W. Schöllkopf, A. S. Gentleman, A. Fielicke, and S. R.

Mackenzie, Angew Chem Int Ed 57, 14822 (2018).

[67] A. D. Becke, J Chem Phys 98, 5648 (1993).

[68] J. P. Perdew, Phys Rev B 33, 8822 (1986).

[69] T. H. Dunning and P. J. Hay, in Modern Theoretical Chemistry, edited by S. H. F. (Springer, Boston, MA, 1977).

[70] D. Andrae, U. Häußermann, M. Dolg, H. Stoll, and H. Preuß, Theor Chim Acta 77, 123 (1990).

[71] M. J. Frisch et al., Gaussian 09, Revision D.01, Gaussian, Inc., 2013.

[72] M. A. Addicoat and G. F. Metha, J Comput Chem 30, 57 (2009).

[73] F. Weigend and R. Ahlrichs, Phys Chem Chem Phys 7, 3297 (2005).

[74] C. Lee, W. Yang, and R. G. Parr, Phys. Rev. B 37, 785 (1988).

[75] B. Miehlich, A. Savin, H. Stoll, and H. Preuss, Chemical Physics Letters 157, 200 (1989).

[76] T. Yanai, D. P. Tew, and N. C. Handy, Chem Phys Lett 393, 51 (2004).

[77] J. P. Perdew, J. Tao, V. N. Staroverov, and G. E. Scuseria, J Chem Phys 120, 6898 (2004).

[78] J. Tao, J. P. Perdew, V. N. Staroverov, and G. E. Scuseria, Phys Rev Lett 91, 146401 (2003).

[79] J. P. Perdew, K. Burke, and M. Ernzerhof, Phys Rev Lett 77, 3865 (1996).

[80] J. P. Perdew, K. Burke, and M. Ernzerhof, Phys Rev Lett 78, 1396 (1997).

[81] Y. Zhao and D. G. Truhlar, J Chem Phys 125, 194101 (2006).

[82] S. Grimme, J. Antony, S. Ehrlich, and H. Krieg, J Chem Phys 132, 154104 (2010).

[83] S. Grimme, S. Ehrlich, and L. Goerigk, J Comput Chem 32, 1456 (2011).

[84] G. Herzberg, Molecular Spectra and Molecular Structure (Krieger Publishing

Company, Malabar, Florida, 1989), Vol. I. Spectra of Diatomic Molecules.

[85] G. Herzberg, Molecular Spectra and Molecular Structure (Krieger Publishing

Company, Malabar, Florida, 1991), Vol. II. Infrared and Raman Spectra of Polyatomic

Molecules.

[86] T. Shimanouchi, Tables of Molecular Vibrational Frequencies Consolidated (Nat.

Stand. Ref. Data Ser., Nat. Bur. Stand., Wahington, D.C., 1972), Vol. 1.

[87] E. M. Cunningham et al., Phys Chem Chem Phys 23, 329 (2021).

[88] B. A. Collings, A. H. Amrein, D. M. Rayner, and P. A. Hackett, J Chem Phys 99, 4174 (1993).

[89] A. Komornicki and R. L. Jaffe, J Chem Phys 71, 2150 (1979).

[90] V. Chernyy, R. Logemann, A. Kirilyuk, and J. M. Bakker, ChemPhysChem 19, 1424 (2018).

[91] A. Fielicke, G. von Helden, G. Meijer, B. Simard, and D. M. Rayner, Phys Chem Chem Phys 7, 3906 (2005).

[92] A. Shayeghi, R. L. Johnston, and R. Schäfer, J Chem Phys 141, 181104 (2014). 
[93] G. Schmid, Chem Soc Rev 37, 1909 (2008).

[94] H.-F. Zhang, M. Stender, R. Zhang, C. Wang, J. Li, and L.-S. Wang, J Phys Chem B 108, 12259 (2004).

[95] S. Vajda and M. G. White, ACS Catal 5, 7152 (2015).

[96] C. Yu, W. Harbich, L. Sementa, L. Ghiringhelli, E. Apra, M. Stener, A. Fortunelli, and H. Brune, J Chem Phys 147, 074301 (2017).

[97] A. S. Wörz, U. Heiz, F. Cinquini, and G. Pacchioni, J Phys Chem B 109, 18418 (2005).

[98] W. D. Schneider, M. Heyde, and H. J. Freund, Chem Eur J 24, 2317 (2018).

[99] G. Pacchioni and H. J. Freund, Chem Soc Rev 47, 8474 (2018).

[100] A. Sanchez, S. Abbet, U. Heiz, W. D. Schneider, H. Häkkinen, R. N. Barnett, and U. Landman, J Phys Chem A 103, 9573 (1999). 